\title{
Endoscopic ultrasound-guided choledochoduodenostomy without fistula dilation using a novel fully covered metallic stent with a 5.9-Fr ultra-thin delivery system
}

Endoscopic ultrasonography-guided choledochoduodenostomy (EUS-CDS) is a potential procedure for primary drainage in unresectable malignant distal biliary obstruction and can replace endoscopic retrograde cholangiopancreatography. However, adverse events following EUS-CDS are occasionally reported, the most common being bile leak due to fistula dilation [1,2]. The safety of EUS-CDS without fistula dilation using two types of thin, fully covered self-expandable metallic stents (FCSEMSs) has been previously reported [3-5]. Here we report a case in which EUS-CDS without fistula dilation was successfully performed using a novel FCSEMS with a 5.9-Fr delivery system (Hanarostent Benefit; M.I.Tech, Seoul, Korea) ( $>$ Fig. 1). A 62-year-old man who had received chemotherapy for unresectable pancreatic body cancer developed a distal biliary obstruction. Computed tomography revealed a $25-\mathrm{mm}$ mass on the pancreatic body and a dilated common hepatic duct (CHD) (\$ Fig.2a). We performed EUS-CDS for primary drainage.

The dilated CHD was localized using a forward-viewing echoendoscope (TGFUC260J; Olympus Medical Systems, Tokyo, Japan) from the duodenal bulb ( Fig. 2 b). First, the CHD was punctured with a 19-gauge needle (EZ Shot 3 Plus; Olympus Medical Systems). Cholangiography revealed a dilated CHD with distal obstruction. Second, a 0.025-inch guidewire (M-Through; ASAHI INTECC Corp., Tokyo, Japan) was inserted into the B4 branch. Fistula dilation was avoided, and the novel FCSEMS $(8 \mathrm{~mm} \times 6 \mathrm{~cm})$ was passed through the duodenum and CHD wall smoothly. Finally, the stent was placed in the CHD from the duodenal bulb (> Fig. 3, \Fig. 4; Video 1).

No adverse events occurred during or after the procedure.

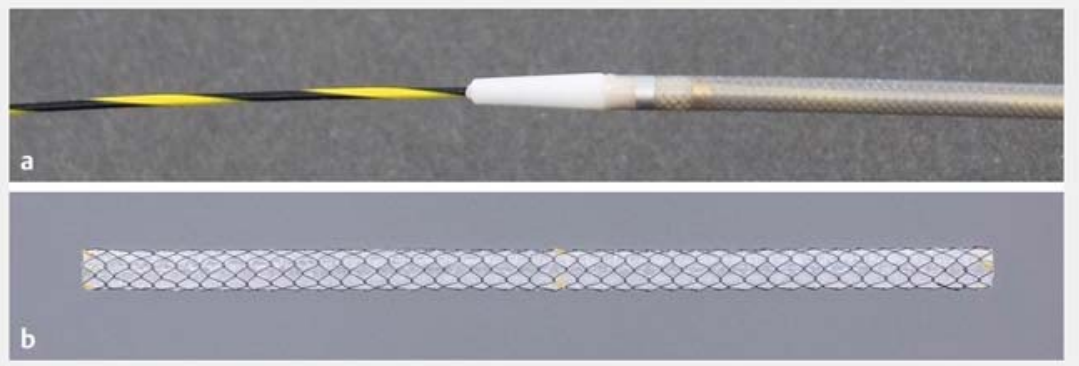

- Fig. 1 Novel fully covered self-expandable metal stent with an ultra-thin delivery system. a The outer sheath of the delivery catheter is size $5.9 \mathrm{Fr}$. b The expanded stent with a braiding design.
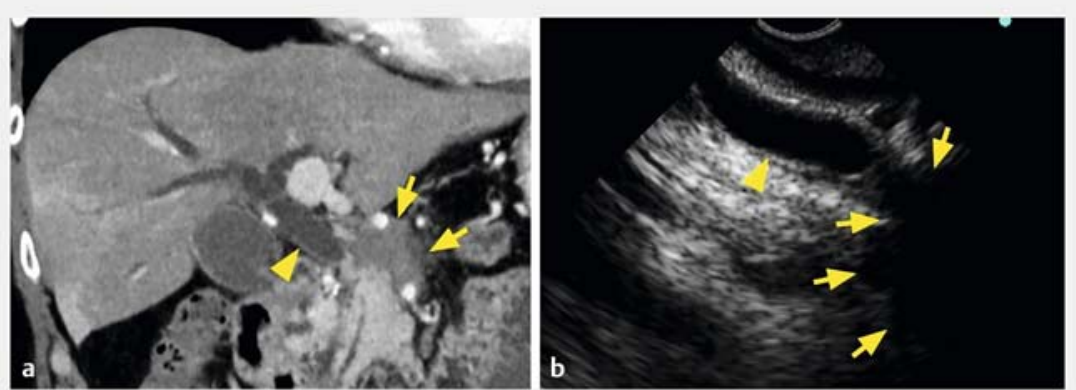

- Fig. 2 Image findings before the procedure. a Coronal computed tomographic image revealing a hypovascular mass of the pancreatic body (arrows) and dilated common hepatic duct (CHD) (arrowhead). b Endoscopic ultrasonography image indicating a hypoechoic mass of the pancreatic body (arrows) and dilated CHD (arrowhead).

In previous reports, EUS-CDS without fistula dilation was performed using the FCSEMSs with a 7-Fr or 7.5-Fr delivery system, with $31.6 \%-100 \%$ technical success rate [3 - 5]. This is the first report discussing EUS-CDS without fistula dilation using a FCSEMS with a 5.9-Fr delivery system, which is the thinnest ever commercially available delivery system and is capable of simpler and safer EUS-CDS procedures.

Endoscopy_UCTN_Code_TTT_1AS_2AD
Acknowledgements

This work was supported in part by The National Cancer Center Research and Development Fund (31-A-13).

\section{Competing interests}

The authors declare that they have no conflict of interest. 

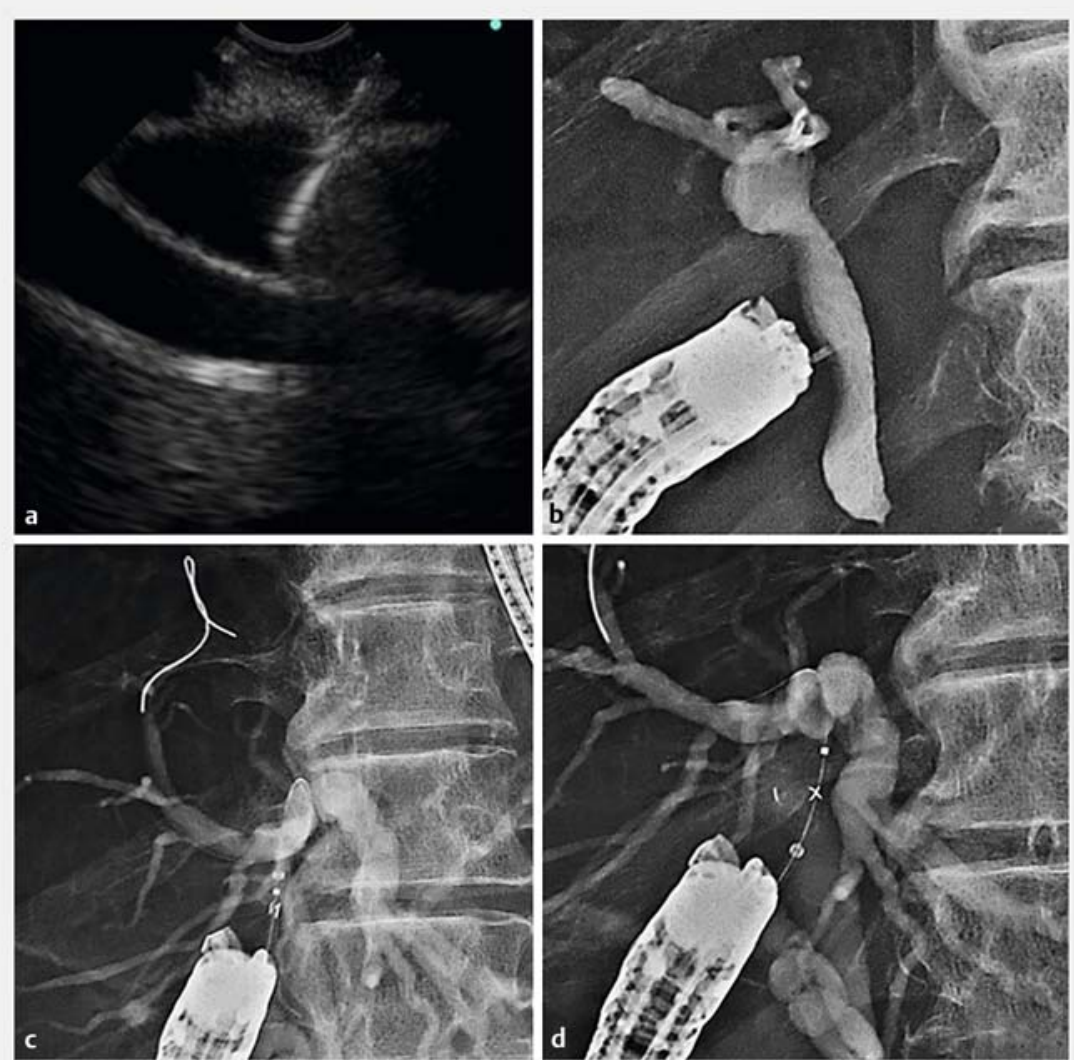

Fig. 3 Endoscopic ultrasonography-guided choledochoduodenostomy without fistula dilation. a The common hepatic duct (CHD) was punctured with a 19-gauge needle. b Cholangiography revealed a dilated CHD with a distal obstruction. c A 0.025 -inch guidewire was inserted into the B4 branch, and the fully covered self-expandable metal stent (FCSEMS) was inserted into the CHD without fistula dilation. $\mathbf{d}$ The FCSEMS was deployed into the CHD.
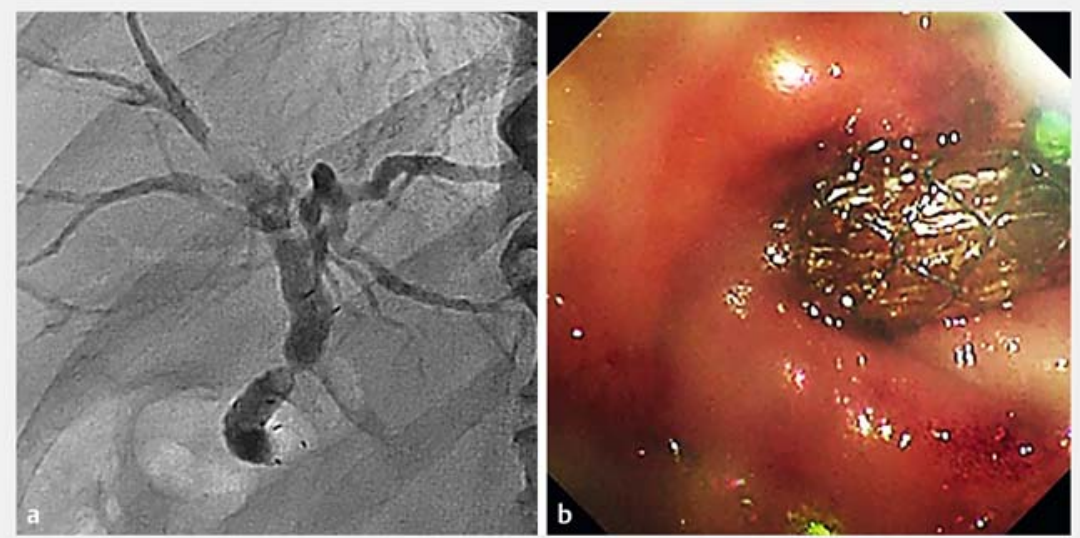

- Fig. 4 Image findings after the procedure. a Fluoroscopic image. b Endoscopic image.
The authors

Takehiko Koga' ${ }^{1}$, Susumu Hijioka ${ }^{1}$, Yuya Hisada ${ }^{1}$, Yuta Maruki ${ }^{1}$, Yoshikuni Nagashio', Takuji Okusaka ${ }^{1}$, Yutaka Saito ${ }^{2}$

1 Department of Hepatobiliary and Pancreatic Oncology, National Cancer Center Hospital, Tokyo, Japan

2 Department of Endoscopy, Gastrointestinal Endoscopy Division, National Cancer Center Hospital, Tokyo, Japan

\section{Corresponding author}

\section{Susumu Hijioka}

Department of Hepatobiliary and Pancreatic Oncology, National Cancer Center Hospital, 5-1-1 Tsukiji, Chuo-ku, Tokyo 104-0045, Japan

Fax: +81-3-3542-3815

shijioka@ncc.go.jp

\section{References}

[1] Kawakubo K, Isayama H, Kato H et al. Multicenter retrospective study of endoscopic ultrasound-guided biliary drainage for malignant biliary obstruction in Japan. J Hepatobiliary Pancreat Sci 2014; 21: 328-334

[2] Wang K, Zhu J, Xing L et al. Assessment of efficacy and safety of EUS-guided biliary drainage: a systematic review. Gastrointest Endosc 2016; 83: 1218-1227

[3] Park DH, Lee TH, Paik WH et al. Feasibility and safety of a novel dedicated device for one-step EUS-guided biliary drainage: a randomized trial. J Gastroenterol Hepatol 2015; 30: 1461-1466

[4] Itonaga M, Kitano M, Hatamaru K et al. Endoscopic ultrasound-guided choledochoduodenostomy using a thin stent delivery system in patients with unresectable malignant distal biliary obstruction: a prospective multicenter study. Dig Endosc 2019; 31: 291-298

[5] Paik WH, Lee TH, Park DH et al. EUS-guided biliary drainage versus ERCP for the primary palliation of malignant biliary obstruction: a multicenter randomized clinical trial. Am J Gastroenterol 2018; 113: 987-997 


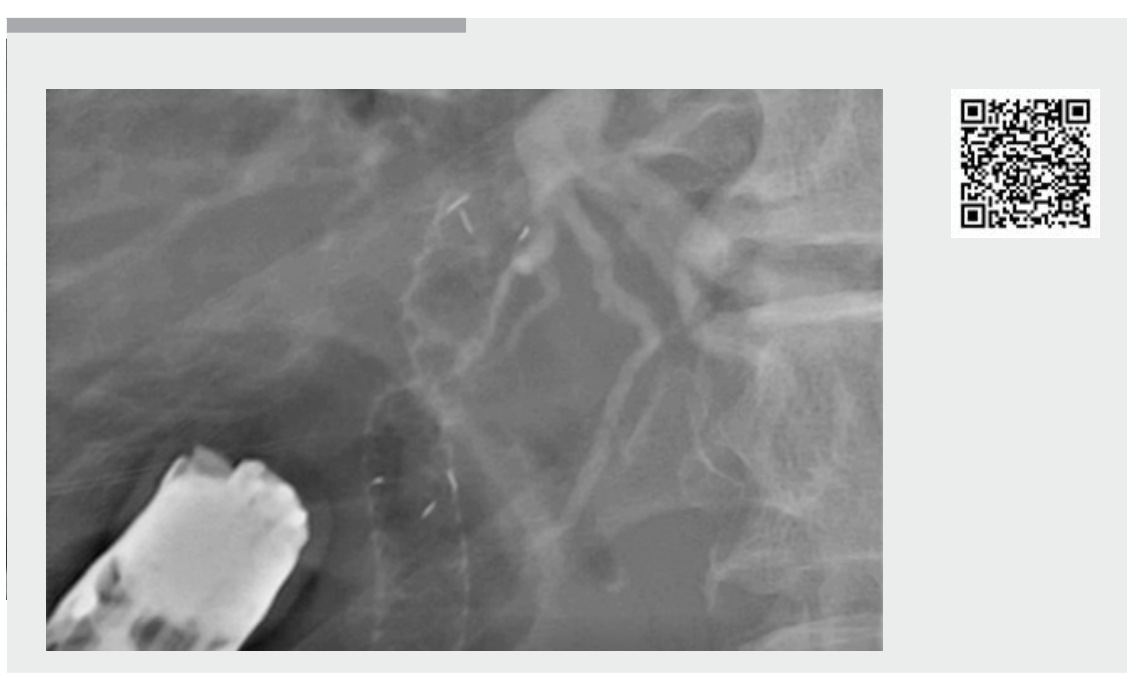

$\checkmark$ Video 1 The video shows an endoscopic ultrasonography-guided choledochoduodenostomy without fistula dilation performed using a novel fully covered self-expandable metal stent with a 5.9-Fr ultra-thin delivery system.

\section{Bibliography}

Endoscopy 2021; 53: E223-E225

DOI 10.1055/a-1244-9651

ISSN 0013-726X

published online 11.9 .2020

(c) 2020. Thieme. All rights reserved.

Georg Thieme Verlag KG, Rüdigerstraße 14, 70469 Stuttgart, Germany

\section{ENDOSCOPY E-VIDEOS}

https://eref.thieme.de/e-videos

Endoscopy E-Videos is a free access online section, reporting 回: on interesting cases and new techniques in gastroenterological endoscopy. All papers include a high quality video and all contributions are freely accessible online.

This section has its own submission website at

https://mc.manuscriptcentral.com/e-videos 